www. revis tad y o. com

\title{
The deferral option in the collective dismissal procedure
}

\author{
La opción de aplazamiento en los expedientes de regulación de empleo
}

Santos Eguren, Pablo Solana y Mercedes Grijalvo

Departamento de Ingeniería de Organización, Administración de Empresas y Estadística. Escuela Técnica Superior de Ingenieros Industriales. Universidad Politécnica de Madrid. C/ José Gutiérrez Abascal, 2. 28006 - Madrid, Spain.

santos.eguren@upm.es, psolana@aticonsult.es, mercedes.grijalvo@upm.es

Fecha de recepción: 11-12-2014

Fecha de aceptación: 08-06-2015

\begin{abstract}
The work in this paper focuses on the integration of the real options theory for organizational projects in the management of Human Resources, and particularly on the inclusion of the deferral option in collective dismissal procedures. This option has been studied and developed to be applied to 'Expediente de regulación de empleo', which is the legal form existing in Spain for the collective termination of employment contracts and which organizations turn to when confronted with a negative financial situation, as a way of maintaining their viability. Two main issues which it is hoped to resolve are examined: the search for a source of uncertainty to make the deferral option viable for this type of projects, and the development of a procedure to obtain the value of the option and therefore facilitate decision making. The analysis performed has enabled us to state that the volatility of demand is the source of uncertainty that makes the option viable. The procedure developed by the binomial tree, which is determined by the evolution of demand, is the tool that enables the value of the option to be found.
\end{abstract}

Keywords: collective dismissal procedure; deferral option; demand; real options; uncertainty.

Resumen: El trabajo presentado en este artículo se focaliza en la integración de la teoría de opciones reales en los proyectos organizativos de gestión de Recursos Humanos, en particular en la incorporación de la opción de aplazamiento a los procedimientos de despido colectivo. El estudio y desarrollo de dicha opción se ha llevado a cabo aplicándolo a los Expedientes de Regulación de Empleo, que es la figura legal existente en España para la extinción colectiva de contratos de trabajo y al que las organizaciones recurren ante una situación económica negativa, con el objetivo de mantener su viabilidad. Dos cuestiones principales se acometen y pretenden resolver, la búsqueda de una fuente de incertidumbre que ponga en valor la opción de aplazamiento para este tipo de proyectos y el desarrollo de un procedimiento que permita obtener el valor de la opción y de esta manera facilitar la toma de decisiones. El análisis realizado ha permitido constatar que la volatilidad de la demanda es la fuente de incertidumbre que pone en valor la opción y la aplicación práctica del procedimiento desarrollado, a partir del árbol binomial que determina la evolución de la demanda, la herramienta que permite obtener el valor de la opción

Palabras clave: expediente de regulación de empleo; opción de aplazamiento; demanda; opciones reales; incertidumbre.

\section{Introduction}

In times of crisis Organizations design projects whose main objective is to reduce costs in order to improve efficiency, which, in many cases, is an attempt to offset the fall in income and profits ensuing from a drop in demand.

To achieve this objective one possibility to which companies have recourse is to terminate the employment contracts, so that the reduction in human resour ces costs will enable them to recover the productivity threshold prior to their current situation and return to profitability in the income statement.
When faced with a period of a continuous fall in profits and productivity, companies choose to apply a Collective Dismissal Procedure (CDP), which will enable them to recover from the negative financial situation in which they find themselves.

Cutting back on human resources may, therefore, be a sustainable benefit in the long term, but three factors must be taken into account before making this kind of decision. The first is the uncertainty regarding a recovery in demand, which can lead to the Organization losing competitiveness through not having the resources required to adapt to an unforeseen change for the better of the situation. The second factor to be con- 
sidered is the compensation to be paid to the workers which can lead to a considerable delay in making any profits. Thirdly, the loss of know-how, since recovering lost skills can be highly complex as taking on new staff involves management costs and a lengthy time period.

By examining what is known about the procedure concerning a CDP, this work sets out to evaluate at what moment it can be best applied by integrating the real options theory into human resource management. The option to be analyzed and developed is the deferral option so that the following question can be addressed: Is it the right time to apply a CDP or can it be postponed for longer?

It is understandable that when faced with a negative financial situation the company management will want to apply a CDP as soon as possible, but if the decision is postponed, it can better position the company with regard to future market developments. For this reason, given that the standard procedure for assessing the right time to apply it does not take account of all the factors that endow such projects with flexibility and those which can also generate uncertainty in the future, this work aims to set a procedure for finding the viability of the deferral option.

Developing a procedure to evaluate the deferral option is also aimed at enhancing management and decisionmaking and providing a step forward in the application of the real options open to human resource ma- nagement, and, therefore, let us continue advancing in this field.

It should not be forgotten that a CDP project has a social cost that not only falls specifically and directly on the workers affected but also on their home environment and society. Therefore, this work aims to be of assistance in improving decision-making in such a sensitive context. If flexibility can be shown regarding future circumstances so that a deferral option can be adopted when faced with a CDP, in the hope that the uncertainty will be clarified, it will at least offer an opportunity to postpone applying the CDP, and should future circumstances improve it may not even be necessary.

In Spain the legislation governing collective employment contract termination projects is applied using a process called 'Expediente de regulación de empleo' (ERE). Although this work focuses on whether a deferral option is applicable to an ERE, the results can be generalized to any collective procedure for the termination of employment contracts in a company. For this reason, the abbreviation CDP will be used except when stating characteristics that are specific to an ERE.

\section{Literature review}

After a review of the literature regarding the application of the real options theory to human resource management, we have seen that there is little research work on this matter, and what there is generally takes a theoretical approach. In particular, no work has been found that specifically deals with the deferral option in a collective human resource reduction project.

It is in the first decade of this century that research studies can be found in the literature that are aimed at going beyond the traditional way of evaluating investment in human resource management, although they are usually theoretical works aimed at applying real options to such management, thereby incorporating any future uncertainties. In this respect, Foote and Folta (2002) present a paper where they suggest that temporary workers represent a real option for postponing taking on, maintaining or reducing permanent staff, which means that to manage the irreversibility of investments in human resources and for making decisions regarding expansion or hiring, real options have to be included taking account of their peculiarities.

Chen and Funke (2002) present a work in which they formulate a model that is an improvement on the traditional one by applying the real options theory to a combination of the level of employment and work time, as a coherent relationship is established between the three specific characteristics in decisions involving jobs, irreversibility, uncertainty and choosing the right time.

Extending the standard model of irreversible investment under uncertainty, Kandel and Pearson (2002) also present research, which, together with the capital they consider partially reversible, includes a second reversible technology that may be interpreted as labour. This means the capital can replace this technology, ensuring that the value of the option does not depend on the degree to which the capital is reversible and on the fact that the next unit of the capital's contribution to profit is limited by the difference in operating costs.

Bhattacharya and Wright (2005), acknowledging the scarce literature available, present a work that takes a theoretical approach as to how to apply real options to human resource management. They consider human resources to be an asset that possesses some intrinsic aspects or capabilities, which are those that create value in Organizations, but which are subjected to uncertainties. It is here that they consider that real options are valuable. They suggest options based on the uncertainty of a return on the investment, which may come about through a loss of know-how or producti- 
vity. When faced with uncertainty as to the number of human resources required they propose creating operational or temporary options with temporary, casual or part-time workers to alter the operational management, which means that an increase or decrease in human resources is subject to optionality. Work formalizes a global theoretical framework embracing the different options of human resource management, although without mathematical quantification models.

Welpe et al., (2007) look deeper into integrating real option models into human resource management and present a work that evaluates human capital by taking the costs incurred and the returns generated. These authors decided to propose the idea of optionality for reducing human resources, considering the underlying issue to be the contribution of the income statement, the exercise price of the compensation for the reduction and the length of exercise time of the human resources in the Organization, although they consider this idea to be difficult to put into practice due to the protective legislation in different countries.

If we summarise the above, it can be said that although there is a clear will to apply the real options theory to human resource management, this will has been based on theory. They believe that every Organization requires a specific application and express the difficulties involved, which are an obstacle for moving forward in this field and for creating specific models that will facilitate integrating the real options model into human resource management.

\section{Scope of application: Collective dismissal procedure, particularized to the Spanish form 'Expediente de regulación de empleo'}

The ERE is the legal form in Spain (Real Decreto-ley, 2012) in line with which Organizations adjust their work contracts as a means of maintaining their viability when faced with a decline in results. The ERE can be definitive or temporary. A definitive ERE leads to the termination of a series of labour contracts, whereas a temporary ERE suspends the labour contracts for a specific period of time, at the end of which the worker once again takes up their job. The decision to apply either of the cases is based on financial, technical, organizational or production reasons. This work focuses on a definitive ERE as we are examining an irreversible project whose objective is to reduce costs indefinitely to overcome a negative financial situation.
The current legislation deems that a series of economic circumstances come together that allow an ERE to be considered when the company's results reveal a negative financial situation such as current or predicted losses or a persistent drop in income or sales. The situation is deemed to be persistent if it occurs for three consecutive quarters.

If an entrepreneur wishes to apply an ERE they must state the causes or reasons behind such, as well as the number and rank of the employees affected, together with the criteria applied, so that the proposed measures are compliant with the legislation in force. The established protocol envisages consultations with the workers' legal representatives of a duration of no more than thirty calendar days with the aim of being able to avoid or reduce any collective dismissals or attenuate their consequences.

The termination of work contracts will generate future cost savings flows, but the downside is that the workers will have to be paid compensation. This compensation is the investment required to implement the ERE. A- ccording to legislation, the amount of compensation to be paid by an entrepreneur is twenty days salary for each year of service with a maximum of twelve monthly payments.

Therefore, it can be said that a company can consider an ERE as a means of regaining viability or profitability when there is a persistent negative financial situation, by terminating a series of contracts. In this way the company reduces the number of human resources in order to reduce fixed operational costs but the downside is that the workers have to be paid compensation.

The two graphs in Figure 1 show the evolution of the number of authorized ERE and the number of workers affected from 2006-2012 (Ministerio de Empleo y Seguridad Social, 2013), and clearly reflect the rise produced from the beginning of the crisis that is currently affecting Spain.

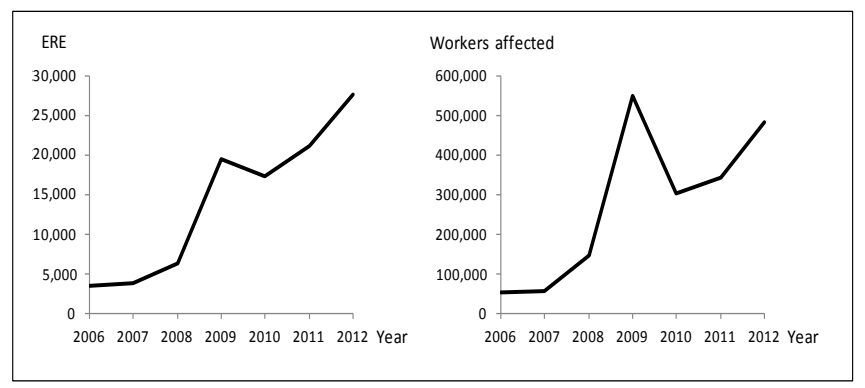

Figure 1. Seven years summary of authorized ERE and workers affected. 


\section{Application tool}

\subsection{Real options}

The real options theory is a financial tool for making a flexible assessment of an Organization's investment project and supersedes the analysis used prior to its appearance, which involved quantifying the project passively. This flexible assessment takes account of future uncertainties, and adds the options to the project, which is a considerable contribution. As Amram and Kulatilaka (1999) point out, these future options are a right but not an obligation for making a particular decision. They are useful to the extent that they are a help when studying the opportunities available for planning and managing strategic investments. Therefore, a person who has a real option has an opportunity to postpone a decision until part of the uncertainty has been resolved.

Real options originated from the theory of financial options on financial assets, and although it has its own philosophy regarding suitability and application, three stages can be considered that are similar to those based on the exercise of financial options. Firstly, an investment is made in the option, then there is a waiting period up to the date of execution until there is a change in the value of the option due to circumstances beyond the control of the bearer, and finally on the date of execution, the bearer of the option depending on how the price of the project has performed, decides whether or not to execute it (Adner and Levinthal, 2004).

Four main types of real options can be considered (Brealey et al., 2010), the expansion option, the deferral option, the option of abandoning and the flexible production option. The aim of this work is to analyze whether a deferral option exists for a CDP project, and should the answer be affirmative to begin to calculate the value of the option. Therefore we will now set out the general concepts for evaluating the deferral option of an investment project.

\subsection{Valuing the deferral option of a project}

The purpose of an investment project is to obtain future positive cash flows as a return on the investment, made normally at the beginning of the project. The analysis of the deferral option evaluates two alternatives; to execute the project immediately or defer it, bearing in mind the possible future evolution of the cash flows and taking as a basis one or more sources of uncertainty, it being important to identify these sources and their behaviour.
The method set out below is based on the binomial tree approach which Cox, et al., (1979) developed for financial options and which is also applicable to real options. The procedure considers a single deferral period but is applicable to multiple periods. It comprises two steps. The first shows how to find the value of the project and of the option at the end of the deferral period. The second explains how to find the present- time value of the option by means of the replicating portfolio concept. Comparing the value of the option with the current value of the project at the present time will enable us to decide whether or not to defer the project.

\subsubsection{Finding the value of the project and the option at the end of the deferral period}

Let us take a project with a present-time investment of 10 , which is expected to generate annual future cash flows, which we shall denote as fo. If a life of $n$ years is considered, these cash flows, discounted at a discount rate of $r$ have a current accumulated value of $F_{0}$, which can be found from the following expression:

$$
F_{0}=\sum_{a=1}^{n} \frac{f_{0}}{(1+r)^{a}}
$$

So, for the project, a present-time value of VP0 is equal to the net worth of all the cash flows, $\mathrm{VP}_{0}=\mathrm{NPV}_{0}=\mathrm{F}_{0}$ $-I_{0}$.

Taking future uncertainties as a basis, we consider the possibility of deferring the project for a period of time. To evaluate whether it is of interest to defer the project we need to know how the cash flows might evolve as this will determine the future value of the project.

On completion of the deferral period two scenarios are possible: one favourable where the cash flows of the project will be higher than $\mathrm{f}_{0}$ and an unfavourable scenario where they are lower. If the cash flows are higher than $\mathrm{f}_{0}$, we call them $\mathrm{f}_{1}$ and if discounted at the discount rate $r$ they have an accumulated value which we call $F_{1}$. If the cash flows are lower than $f_{0}$, we call them $\mathrm{f}_{2}$ and if discounted they have an accumulated value which we call $F_{2}$. Since the investment cost is equal to $\mathrm{I}_{0}$, which is deemed to be invariable, the value of the project at the end of the deferral period will be, respectively, $\mathrm{VP}_{1}=\mathrm{NPV}=\mathrm{F}_{1}-\mathrm{I}_{0}$ for the favourable scenario and $V P_{2}=N P V_{2}=F_{2}-I_{0}$ for the unfavourable one.

Having found the value of the project at the end of the deferral period, it must be decided whether or not to execute it. If the value of the project is positive it will be 
executed, while if the value of the project is negative it will not be executed and the option will be worth 0 . Therefore, the value of the option VO is expressed for each scenario in the following way:

$$
\begin{aligned}
& \text { Favourable scenario } \mathrm{VO}_{1}=\max \left(\mathrm{F}_{1}-\mathrm{I}_{0}, 0\right) \\
& \text { Unfavourable scenario } \mathrm{VO}_{2}=\max \left(\mathrm{F}_{2}-\mathrm{I}_{0}, 0\right)
\end{aligned}
$$

Figure 2 illustrates the binomial diagram with the possible evolution of the expected flows, the value of the project and the value of the option.

\subsubsection{Calculating the value of the option at the present time}

To calculate the present-time value of the option, we shall use the replicating portfolio concept. This concept was one of the ideas expressed by Black and Scholes (1973) and is based on the fact that a portfolio can be made up of shares and a loan, in a way that the yield of the portfolio is exactly the same as the yield of the purchase option over the shares, that is, they must have the same cash flows.

Applying the equivalent portfolio concept to find the value of the deferral option $\mathrm{VO}_{0}$, is based on the underlying asset equivalent to the financial shares being considered here as the investment project and that a portfolio can be constructed made up of "m" units of the project plus a loan "b", resulting in the cash flows generated by the portfolio being exactly equal to those of the deferral option.

The value of the option $\mathrm{VO}_{0}$ at the present time (Figure 2 , node 0 ) can therefore be expressed by a portfolio comprising ' $m$ ' units of the value of the investment project $\mathrm{VP}_{0}$ plus the value of the loan ' $\mathrm{b}$ ':

$$
\text { Node } 0: \mathrm{VO}_{0}=\mathrm{m} \cdot \mathrm{VP}_{0}+\mathrm{b}
$$

Knowing the value of the project and the option in two different assumptions (Figure 2, nodes 1 and 2), and knowing that the value of the loan is capitalised at the risk-free interest rate $r$, the following equations can be considered:

$$
\begin{aligned}
& \text { Node 1: } \mathrm{VO}_{1}=\mathrm{m} \cdot \mathrm{VP} \\
& \text { Node } 2:(1+r) \cdot b \\
& \mathrm{VO}_{2}=\mathrm{m} \cdot \mathrm{VP} \\
& 2+(1+r) \cdot b
\end{aligned}
$$

Solving the two equations simultaneously [5] and [6], will give us the values of ' $m$ ' and of the loan 'b', which define the composition of the replicating portfolio. Once the composition of the portfolio is known, we can calcu-

\begin{tabular}{|c|c|}
\hline $\begin{array}{l}\text { Investment } \mathrm{I}_{0} \\
\text { Cash flows } \mathrm{f}_{0} \\
\text { Cash flows discountec } \\
\mathrm{F}_{0}=\sum_{\mathrm{a}=1}^{\mathrm{n}} \frac{\mathrm{f}_{0}}{(1+\mathrm{r})^{\mathrm{a}}} \\
\text { Value of a project } \\
\mathrm{VP}_{0}=\mathrm{NPV}_{0}=\mathrm{F}_{\mathrm{O}^{-} \mathrm{I}_{0}} \\
\mathrm{Value} \mathrm{of} \mathrm{the} \mathrm{option} \\
\mathrm{VO}_{0}=\mathrm{mVP}_{0}+\mathrm{b}\end{array}$ & $\begin{array}{l}\text { (1) Investment } \mathrm{I}_{0} \\
\text { Cash flows } \mathrm{f}_{1}>\mathrm{f}_{0} \\
\text { Cash flows discounted } \mathrm{F}_{1}=\sum_{\mathrm{a}=1}^{\mathrm{n}} \frac{\mathrm{f}_{1}}{(1+\mathrm{r})^{\mathrm{a}}} \\
\text { scenario } \\
\text { Value of a project } \mathrm{VP}_{1}=\mathrm{NPV}_{1}=\mathrm{F}_{1} \mathrm{I}_{0} \\
\text { Value of the option } \mathrm{VO}_{1}=\max _{\left(\mathrm{F}_{1}-\mathrm{I}_{0}, 0\right)=}=\mathrm{mVP}_{1}+(1+\mathrm{r}) \mathrm{b} \\
\text { (2) } \\
\text { Investment } \mathrm{I}_{0} \\
\text { Cash flows } \mathrm{f}_{2}<\mathrm{f}_{0} \\
\text { Cash flows discounted } \mathrm{F}_{2}=\sum_{\mathrm{a}=1}^{\mathrm{n}} \frac{\mathrm{f}_{2}}{(1+\mathrm{r})^{\mathrm{a}}} \\
\text { Value of a project } \mathrm{VP}_{2}=\mathrm{NPV}_{2}=\mathrm{F}_{2}-\mathrm{I}_{0} \\
\text { Value of the option } \mathrm{VO}_{2}=\max \left(\mathrm{F}_{2}-\mathrm{I}_{0}, 0\right)= \\
=\mathrm{mVP}_{2}+(1+\mathrm{r}) \mathrm{b}\end{array}$ \\
\hline
\end{tabular}
late its value in node 0 , which will give the value of the present-time option $\mathrm{VO}_{0}$.

If the value of the option in node 0 is greater than the value of the project in this node, we defer the project.

Figure 2. Binomial tree of a period for a deferral option

\section{Finding the scope of the CDP}

To calculate the value of the deferral option, the scope of the CDP needs to be known in line with the company's economic circumstances.

The amount of human resources fixed costs that need to be reduced for the company to return to profitability, determines the number of contracts to be terminated. We will now set out the evolution of the financial data that will give the company's operating income in the different stages of the CDP decision-making process and the ensuing cost savings.

Let us assume that a company with an annual income of $\mathrm{V}_{\mathrm{O}}$, and variable costs of $\mathrm{C}_{\mathrm{OV}}$, achieves a contribution margin $\mathrm{M}_{\mathrm{O}}$ (subscript 'O' represents the company's situation prior to the economic decline). The company's total fixed costs are $\mathrm{C}_{\mathrm{OF}}$, which, if subtracted from the contribution margin will generate an annual operating income $R_{0}$, which means the annual profi- tability compared to income will be $\mathrm{Y}_{\mathrm{O}}=\mathrm{R}_{\mathrm{O}} / \mathrm{N}_{\mathrm{O}}$. The company's annual cash flow is $\mathrm{fO}$, and therefore, the company value $V_{E_{O}}$ is the sum of the flows discounted for a life of $n$ years, $F_{0}$.

For market reasons a drop in the company's income occurs up to $V_{A}$, placing it in a difficult financial situation (subscript ' $A$ ' defines the company's negative financial situation prior to applying the CDP). Since the variable costs allocated to the income statement correspond to the products sold, it can be inferred that they are directly proportional to the income. To simplify matters this proportionality is assumed to be maintained regardless of the turnover, for which reason the variable 
costs drop in equal proportion to the income to $C_{A V}$, which also means that the contribution margin drops in the same proportion to $\mathrm{M}_{\mathrm{A}}$. Since the fixed costs $\mathrm{C}_{\mathrm{OF}}$ remain the same, given the company's si- tuation, under normal circumstances they should not increase, the company's annual operating income falls to $R_{A}$, the company's new annual profitability now being $Y_{A}=R_{A}$ l $V_{A}$. The company's annual cash flow also falls to $f_{A}$ and consequently, the value of the company $V E_{A}$ depreciates since the sum of the discounted cash flows, $F_{A}$ also falls.

In order to return to a profitability that will place the company in a viable position, it is decided to implement a CDP by reducing its fixed human resources costs of COF to CEF (subscript 'E' defines the company's situation after the CDP) that an annual operating income $R_{E}$ is generated that will provide an objective profitability of $Y_{E}=R_{E} / V_{A}$. The CDP about to be implemented will therefore mean a reduction in contracts that will lead to an annual saving in fixed costs equal to $\mathrm{C}_{\mathrm{OF}}-\mathrm{C}_{\mathrm{EF}}$. To implement this, the company will have to make an investment IE, which is the compensation to be paid. After implementing the CDP the company's annual cash flow will recover up to $f_{E}$ and the company value $V E_{E}$, which, in this case, will be the sum of the discounted flows $F_{E}$ less the compensation $I_{E}$, which will also recover.

\section{Study and application of the deferral option in a CDP}

\subsection{Deducting the source of uncertainty}

Having established the scope of application, the value of the deferral option and the procedure to evaluate the scope of the CDP, the next objective is to find out if the CDP projects are subject to sources of uncertainty that can make the real options theory viable.

The first thing to consider when planning to defer a CDP project is to know that it can cause any future savings flows generated by a CDP project to vary. Initially, there does not appear to be anything intrinsic to the project that will cause these flows to vary once it has been implemented, since the factors involved, which are compensation and a series of contracts to be terminated, are quite clear right from the start. Therefore, the annual cost savings generated by no longer having to pay the workers will be the same whether or not the CDP is implemented at the present time or in the future. This will lead us to think that there is no sense in deferring the CDP, since if it is delayed the cash flows of the deferral period will be lost.

It could therefore be said that a CDP project, because of the need to recover a company's viability, is a closed project with fixed flows and invariables and should be implemented at the present time. Does this mean abandoning the opportunity to make use of the deferral option in a CDP project? Although it would appear so, having gone beyond the first impression, the factor that can make the deferral option viable is the variability of demand if we take account of its impact on the company's operating income. If the prospects are uncertain the variability of demand entails a variability in the company's income, which alters the operating income, which in turn determines the scope of the CDP to be implemented.

Therefore, the variability of demand implies a future uncertainty that will require the termination of work contracts to a higher or lesser degree, which in turn implies a variability in the value of the company, and this makes the deferral option viable.

\subsection{Procedure for calculating the value of the deferral option}

The procedure for calculating the value of the deferral option is based on the binomial model presented by Copeland and Antikarov (2001) for the option of contracting a project. In this case, the company subjected to the CDP is the project to be valued while the investment in the project is the compensation to be paid to the workers.

This model can be adopted because, as previously explained, the value of the company and the scope of the CDP are intrinsic and simultaneously connected, so they are interdependent. Moreover adapting the model to this case makes it more complicated to apply. This is because while our authors state that a company's value is subordinated to a fixed value, in our case the variable value of the company is intrinsically related to another variable value, which is the scope of the CDP.

The procedure comprises five steps:

a) Find the value of the expected income in all the nodes of the binomial tree according to the volatility of demand.

b) Having the value of the expected income, the operating income is calculated in all the nodes and by taking the operating income the cash flow is calculated.

c) Having found the company cash flow, the value of the company is calculated in each node without implementing the CDP. 
d) Having found the value of the company, a decision is made for each node as to whether or not it is necessary to implement a CDP, in accordance with the profitability target agreed.

- If there is no CDP the company value re mains the same.

- If a CDP is to be implemented the scope required to meet the profitability target must be calculated. When the scope is known, we have the company value after the CDP.

e) When we have the company value after the decision to implement the CDP or not, we can now begin to calculate the deferral option for the nodes to which the CDP must be applied, by applying the replicating portfolio concept, starting out from the end nodes

Next section will show how the procedure is applied to a real case in which a five-year term is considered, since we believe it is the minimum period for considering the future evolution of demand.

\subsection{Application to a real case}

In 2012 one of Spain's major security companies considered a collective termination of employment since it had been in a negative economic situation for three consecutive quarters.

In 2011 before its situation deteriorated the company had an annual income of $470 \mathrm{MM} €$ (millions of euros) through having provided its service to 765,000 clients. The variable costs of $20 \mathrm{MM} €$ were low in comparison to income since the major cost was the $350 \mathrm{MM} €$ in HR. The company had other fixed costs of $40 \mathrm{MM} €$, a sum of $4 \mathrm{MM} €$ in depreciation and around $2 \mathrm{MM} €$ in financial expenses. The operating income, with 30 $\%$ company tax showed a profit of $37.8 \mathrm{MM} €$ and a before-tax profitability over income of $11.5 \%$.

In 2012 the company showed a deterioration in its operating income with an annual income of 399.3 MM $€$ due to a fall in the number of clients to 650,000 . The variable costs dropped to $17 \mathrm{MM} €$. HR costs and other fixed costs practically remained the same, which meant that since income fell and the fixed costs remained the same, the operating income showed a loss of 13.6 MM $€$ and a before-tax profitability over income of $-3.4 \%$.

The company's operating income for 2011 and 2012 is set out in Table 1 and shows how the data evolved. The same table also shows the before and after tax profitability and the annual cash flow on adding the depreciation to the result after taxes. Thus, the deterioration of the situation can be seen since the cash flow dropped from 41.8 $\mathrm{MM} €$ to $-9.6 \mathrm{MM} €$, which meant the company no longer had a positive value.

\begin{tabular}{|l|r|r|}
\hline Income statement & \multicolumn{1}{|c|}{2011} & \multicolumn{1}{|c|}{2012} \\
\hline Income & $\mathbf{4 7 0 , 0 0 0 , 0 0 0 . 0}$ & $\mathbf{3 9 9 , 3 4 6 , 4 0 5 . 2}$ \\
Variable costs & $-20,000,000.0$ & $-16,993,464.1$ \\
\cline { 2 - 3 } Contribution margin & $\mathbf{4 5 0 , 0 0 0 , 0 0 0 . 0}$ & $\mathbf{3 8 2 , 3 5 2 , 9 4 1 . 2}$ \\
\hline Personnel costs & $-350,000,000.0$ & $-350,000,000.0$ \\
\cline { 2 - 3 } Contr.Margin - Personnel costs & $\mathbf{1 0 0 , 0 0 0 , 0 0 0 . 0}$ & $\mathbf{3 2 , 3 5 2 , 9 4 1 . 2}$ \\
\hline Other fixed costs & $-40,000,000.0$ & $-40,000,000.0$ \\
\hline Depreciation & $-4,000,000.0$ & $-4,000,000.0$ \\
\hline Operating income & $\mathbf{5 6 , 0 0 0 , 0 0 0 . 0}$ & $\mathbf{- 1 1 , 6 4 7 , 0 5 8 . 8}$ \\
\hline Financial expenses & $-2,000,000.0$ & $-2,000,000.0$ \\
\hline Profit before tax & $\mathbf{5 4 , 0 0 0 , 0 0 0 . 0}$ & $-\mathbf{- 1 3 , 6 4 7 , 0 5 8 . 8}$ \\
\hline Taxes (30\%) & $-16,200,000.0$ & 0 \\
\hline Profit & $\mathbf{3 7 , 8 0 0 , 0 0 0 . 0}$ & $\mathbf{- 1 3 , 6 4 7 , 0 5 8 . 8}$ \\
\hline Profitability before tax & $\mathbf{1 1 . 4 9}$ & $\mathbf{- 3 . 4 2}$ \\
\hline Profitability after tax & $\mathbf{8 . 0 4}$ & $\mathbf{- 3 . 4 2}$ \\
\hline Cash flow & $\mathbf{4 1 , 8 0 0 , 0 0 0 . 0}$ & $-\mathbf{9 , 6 4 7 , 0 5 8 . 8}$ \\
\hline
\end{tabular}

Table 1. Operating income for the years 2011 and 2012

In order to recover viability, the company reached an agreement with the social forces to implement a CDP to be able to return to a before-tax profitability of $8 \%$. However, the company could also wait for one year to see what would happen to the market but wanted to know the value of deferring the decision.

We will now calculate the deferral option value for a fiveyear term. The procedure set out can be applied to a longer term. The steps are as follows:

a) Taking the present-time value of the income, 399.3 MM $€$, we firstly find the value of the company income in each node by configuring the binomial income tree (Figure 3 ), obtained with the $u$ and $d$ factors (up and down), following the multiplying method set by Cox et al., (1979). These factors are obtained for a standard deviation $\sigma$ of $15 \%$ in demand, a period $T$ of one year and $n=1$ since only one subinterval is considered in the year:

$$
\begin{array}{r}
u=e^{\sigma \sqrt{T / n}}=1.162 \\
=e^{-\sigma \sqrt{T / n}}=\frac{1}{u}=0.861 \\
{[7]^{u}}
\end{array}
$$

The binomial tree with the forecast evolution of future income, based on this multiplying method, takes on a lognormal distribution, which, since it is not negative, is considered by many authors to be that which best fits and is plausible for the characteristics of demand (Avanzi et al., 2013; Copeland and Antikarov, 2001).

The neutral risk probabilities, $p$ and 1-p for an annual risk-free rate $r$ of $10 \%$ are as follows: 


$$
\mathrm{p}=\frac{1+\mathrm{r}-\mathrm{d}}{\mathrm{u}-\mathrm{d}}=0.7947(79.47 \%) \quad 1-\mathrm{p}=\frac{\mathrm{u}-1-\mathrm{r}}{\mathrm{u}-\mathrm{d}}=0.2053(20.53 \%)
$$

b) By taking the expected income in each node, the expected cash flow for each node can be calculated (Figure 3). To calculate the cash flow, the variable costs that are proportional to income and represent a value equal to $4,26 \%$ of income, are deducted from the income, as are the fixed costs, $350 \mathrm{MM} €$ of personnel costs, the $40 \mathrm{MM} €$ of other fixed costs and 4 $\mathrm{MM} €$ depreciation. The financial costs of $2 \mathrm{MM} €$ are also deducted and once the before-tax profits have been found the final profit is obtained after deducting company tax at a $30 \%$ rate. The $4 \mathrm{MM} €$ in depreciation are added to this result to obtain the cash flow.

So that it can be visualised how the calculations are performed, each step of these calculations is shown for node $M$, the same method being applied for the other nodes. The cash flow calculation for node $M$ before implementing the CDP is as follows:

\begin{tabular}{ll} 
& \\
Income & 399.3 \\
Variable costs $(4.26 \%)$ & -17.0 \\
Personnel costs & -350.0 \\
Other fixed costs & -40.0 \\
Depreciation & -4.0 \\
Financial expenses & -2.0 \\
\cline { 2 - 2 } Profit before tax & -13.6 \\
Taxes (30 \%) & 0.0 \\
\cline { 2 - 2 } Profit & -13.6 \\
Depreciation & 4.0 \\
\cline { 2 - 2 } Cash flow & $-9.6 \mathrm{MM} €$
\end{tabular}

c) Taking the expected cash flow, the company value is calculated in each node for a 10 year life span, discounting the annual flows at the discount rate of $10 \%$ (Figure 3 ).

The company value in node $\mathrm{M}$ before implementing the CDP is as follows:

$$
\mathrm{VE}(\text { node } \mathrm{M})=\sum_{\mathrm{a}=1}^{\mathrm{n}} \frac{\mathrm{f}_{0}}{(1+\mathrm{r})^{\mathrm{a}}}=\sum_{\mathrm{a}=1}^{10} \frac{-9.6}{1.1^{\mathrm{a}}}=-59.3 \mathrm{MM} €
$$

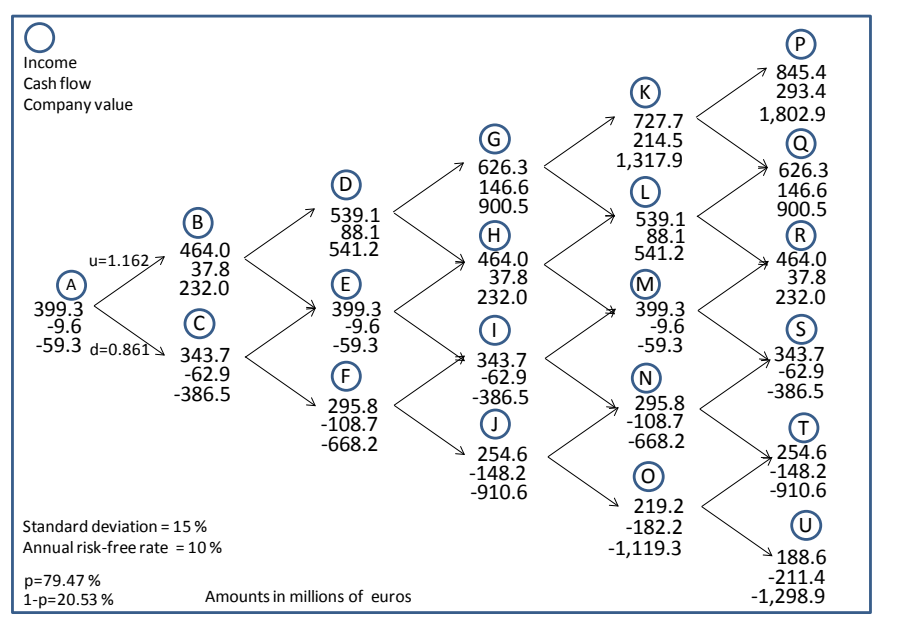

Figure 3. Binomial tree with income, cash flow and the value of the company without the CDP. 
d) Depending on the company value it is decided whether or not there is a need to implement the CDP in each node. Since nodes B, D, G, H, K, L, P, Q and $R$ have positive results and, therefore, a positive company value, the CDP is not implemented.

For the nodes that have a zero or negative company value, the scope required of the CDP to achieve an $8 \%$ profitability is calculated and then the value the company will have after the CDP can be found.

For each of these nodes Table 2 shows the income, total costs, cost saving in human resources, cash flow and the company value after implementing the CDP. This is found after discounting the cash flows so that the total discounted amount is reduced by the compensation to be paid to the workers, which is equal to an annual salary, that is, a year's savings.

Nodes $F, J, N, O, T$ and $U$ consider a situation where even if a CDP is implemented with the purpose of reaching a before-tax profitability of $8 \%$, a positive value is not achieved for the company since it has to pay high compensation, leading to the company lacking viability with a value of zero euros.

\begin{tabular}{|c|c|c|c|}
\hline Nodes & $A, E, M$ & C, I, S & $\mathrm{F}, \mathrm{N}$ \\
\hline Income & 399.3 & 343.7 & 295.8 \\
\hline Costs & 377.0 & 324.5 & 279.3 \\
\hline Annual cost saving & 45.6 & 94.4 & 136.4 \\
\hline Cash flow & 26.4 & 23.2 & 20.6 \\
\hline Value of the company & 116.4 & 48.4 & 0.0 \\
\hline Nodes & $\mathrm{J}, \mathrm{T}$ & 0 & $U$ \\
\hline Income & 254.6 & 219.2 & 188.6 \\
\hline Costs & 240.4 & 206.9 & 178.1 \\
\hline Annual cost saving & 172.6 & 203.7 & 172.6 \\
\hline Cash flow & 18.3 & 16.3 & 14.6 \\
\hline Value of the company & 0.0 & 0.0 & 0.0 \\
\hline
\end{tabular}

Table 2. Company value in the nodes where a CDP is required to be applied.
The calculation in node $\mathrm{M}$ to reach an $8 \%$ profitability with the CDP is:

\begin{tabular}{ll} 
Income & \multicolumn{1}{l}{399.3} \\
Variable costs $(4.26 \%)$ & -17.0 \\
Personnel costs & -304.0 \\
Other fixed costs & -40.0 \\
Depreciation & -4.0 \\
Financial expenses & -2.0 \\
\cline { 2 - 2 } Profit before tax & 31.9 \\
Taxes (30 \%) & -9.5 \\
\cline { 2 - 2 } Profit & 22.4 \\
Depreciation & 4.0 \\
\cline { 2 - 2 } Cash flow & $26.4 \mathrm{MM} €$
\end{tabular}

The annual cost saving in personnel in node $\mathrm{M}$ with the $\mathrm{CDP}$ is $45.6 \mathrm{MM} €$

(350-304.4).

With the above data the company value in node $M$ after the CDP, with a compensation I of a year's salary is: e) Having found the company value in each node, by using the equivalent portfolio concept, the value of the deferral option is calculated in the nodes where the CDP needs to be implemented, beginning at the end nodes and continuing towards the beginning of the binomial tree.

In each node, comparing the company value and the option value will decide whether or not to defer the CDP. If the deferral option value is greater than the company value it should be deferred.
Here the company is equivalent to the project, so the equivalent portfolio will be made up of " $m$ " units of company value and a loan "b". For those nodes, the values of ' $m$ ' and ' $b$ ', the deferral option value, the company value and the decision to be adopted are:

Nodes A, E, M: $m=0.2968 ; b=148.3$

value of the company $=116.4$; value of the option $=130.7$

decision $=$ to defer 
Nodes C, I: $\quad m=0.2147 ; b=130.4$

value of the company $=48.44$; value of the option $=47.4$

decision $=$ not to defer

For node $\mathrm{M}$ the calculation is as follows:

Node R: $\quad \mathrm{VO}_{\mathrm{R}}=\mathrm{m} \cdot \mathrm{VE}_{\mathrm{R}}+(1+\mathrm{r}) \cdot \mathrm{b} ; \quad 232.0=\mathrm{m} \cdot$ $232.0+1.1 \cdot b \quad[11]$

Node S: $\quad V_{S}=m \cdot V E_{s}+(1+r) \cdot b ; \quad 48.4=m \cdot$ $(-386.5)+1.1 \cdot b \quad[12]$
Solving the two equations simultaneously [11] and [12], gives $m=0.2968$ and $b=148.3$ and then the portfolio value is calculated, that is, the option, in node $\mathrm{M}$ :

Node $\mathrm{M}: \quad \mathrm{VO}_{\mathrm{M}}=\mathrm{m} \cdot \mathrm{VE}_{\mathrm{M}}+\mathrm{b}=0.2968 \cdot(-59.3)+$ $148.3=130.7 \mathrm{MM} € \quad$ [13]

Figure 4 depicts the binomial tree with all the results obtained and the decision whether or not to defer.

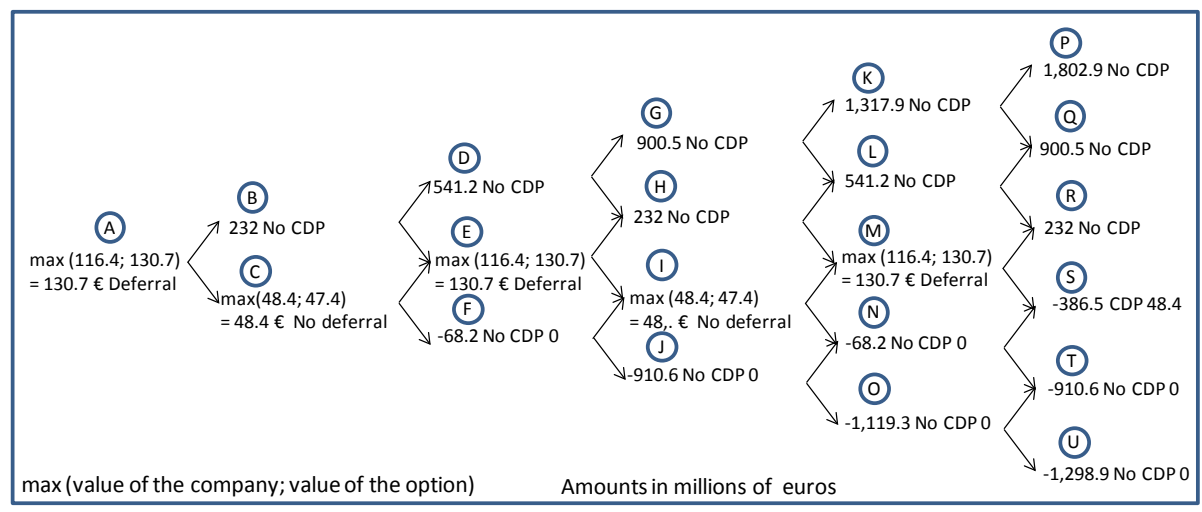

Figure 4. Binomial tree with the results obtained.

The resulting value in node $A$ for the option is 130.7 $\mathrm{MM} €$, greater than the value of $116.4 \mathrm{MM} €$ for the company if the CDP is applied at the present time, therefore the company has the option to defer.

If the standard deviation of the demand were $10 \%$ instead of $15 \%$, that is to say a demand with less volatility, the value of the deferral option in node A would be less, having a value of $95.9 \mathrm{MM} €$. This was to be expected as the uncertainty fell and fits in with the premise that a rise in uncertainty increases the option value. In this case, since the value of the deferral option is less than 116.4 MM $€$, the CDP would not require a deferral.

Figure 5 shows a graph comparing the present-time company value after the CDP and the option value for different values of standard deviation, keeping the other parameters the same. Equilibrium is produced for a standard deviation of $12.97 \%$.

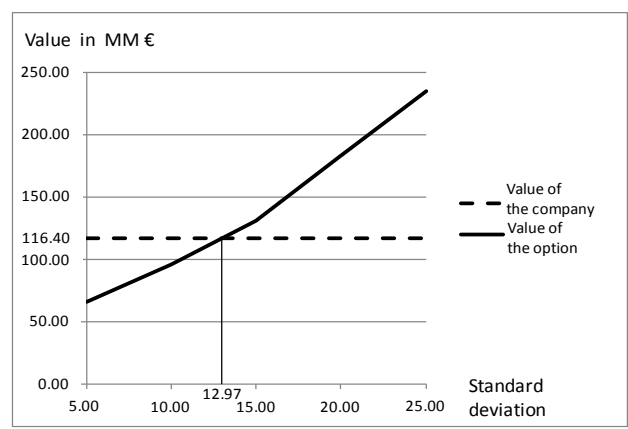

Figure 5. Company and option values for different standard deviations

In this way, the company can see the sensitivity analysis according to the volatility of demand after setting the different feasible scenarios. Therefore, the results obtained allow the company to position itself in the best possible way for any decision-making. 


\section{Conclusion}

The aim of this work has been to approach the possibility of integrating the real options theory into a CDP project, which meant finding a future uncertainty that would make this theory valid. An initial analysis appeared to indicate there was no such uncertainty as the future savings flows of a CDP are fixed and invariable. However, it was seen that the volatility of demand is a factor since it adds uncertainty to the company's operating income because the scope of a CDP project depends on this income.

By taking demand as a source of uncertainty, it has been defined conceptually how the deferral option value can be found and a calculation procedure has been developed. This procedure can be diversified using a multivariate analysis based on the variability of the different parameters that come into play.

The practical explanation of the developed procedure by taking a demand that is configured in a discrete manner has enabled us to verify the difference between taking account or not of future flexibility when it comes to deciding on the right moment to implement the CDP.

We understand that integrating real options into human resource management may be worth considering bearing in mind the scarcity of existing research. However, to a larger extent the CDP deferral option is a contribution worth considering for facing up to a current problem that generates considerable personal and social costs. If the best time to decide whether or not to implement a CDP is accompanied by an informed decision on whether to defer the CDP until later, when the future market evolution will lead to a less demanding CDP project, we will have been successful in mitigating the effects.

\section{References}

ADNER, R., and LEVINTHAL, D. (2004). "What is not a real option: Considering boundaries for the application of real options to business strategy». The Academy of Management Review, 29 (1), pp. 74-85.

AMRAM, M., and KULATILAKA, N. (1999). Real Options: Managing strategic investment in an uncertain world, Boston, MA: Harvard Business School Press. ( $1^{a}$ ed. en español), Barcelona: Ediciones Gestión 2000, S.A.

AVANZI, B., BICER, I., DE TREVILLE, S., and TRIGEORGIS, L. (2013). «Real options at the interface of finance and operations: exploiting embedded supply chain real options to gain competitiveness». The European Journal of Finance, 19 (7-8), pp.760778.
BHATTACHARYA, M., and WRIGHT, P.M. (2005). «Managing human assets in an uncertain world: Applying real options theory to HRM». International Journal of Human Resource Management, 16 (6), pp. 929-948.

BLACK, F., and SCHOLES, M. (1973). «The pricing of options and corporate liabilities». Journal of political economy, 81, pp. 637-654.

BREALEY, R., MYERS, S., and ALLEN, F. (2010). Principles of Corporate Finance, The McGrawHill Companies. (4 ${ }^{a}$ ed. en español), México, D.F: McGraw-Hill/Interamericana Editores, S.A. de C.V.

CHEN, Y.F., and FUNKE, M. (2002). «Working time and employment under uncertainty». Studies in Nonlinear Dynamics and Econometrics, 8 (3), article 5.

COPELAND, T., and ANTIKAROV, V. (2001). Real Options, a practitioner's guide, Texere LLC, New York.

COX, J., ROSS, S., and RUBISTEIN, M. (1979). «Options pricing: a simplified approach». Journal of Financial Economics, 7, pp. 229-263.

FOOTE, D.A., and FOLTA, T.B. (2002). «Temporary workers as real options». Human Resource Management Review, 12 (4), pp. 579-597.

KANDEL, E., and PEARSON, N.D. (2002). «Option value, uncertainty, and the investment decision». Journal of Financial and Quantitative Analysis, 37 (3), pp. 341-374.

MINISTERIO DE EMPLEO Y SEGURIDAD SOCIAL, ESTADISTICAS. (2013). «C o n d i ciones de trabajo y relaciones laborales, Regulación de empleo, Boletín de estadísticas laborales». www.empleo.gob.es/estadisticas/bel/REG/ index.htm.

REAL DECRETO-LEY 3/2012, DE 10 DE FEBRERO. (2012). "Medidas urgentes para la reforma del mercado laboral». Boletín Oficial del Estado A-2012-2076, 12483-12546. www.boe.es/boe/ dias/2012/02/11/pdfs/BOE-A-2012-2076.pdf.

WELPE, I., LUTZ, S., and BARTHEL, E. (2007). «The theory of real options as theoretical foundation for the assessment of human capital in organizations». Zeitschrift Für Personalforschung, 21 (3), pp. 274294. 